\title{
Các nhà khoa học nội lực Việt Nam có trích dẫn hàng đâu thế giới làm việc trong môi trường như thế nào?
}

\author{
Nguyễn Minh Hoàng \\ Trung tâm Nghiên cứu Xã hội Liên ngành \\ Trường đại học Phenikaa, Việt Nam
}

Ngày 03 tháng 11 năm 2021

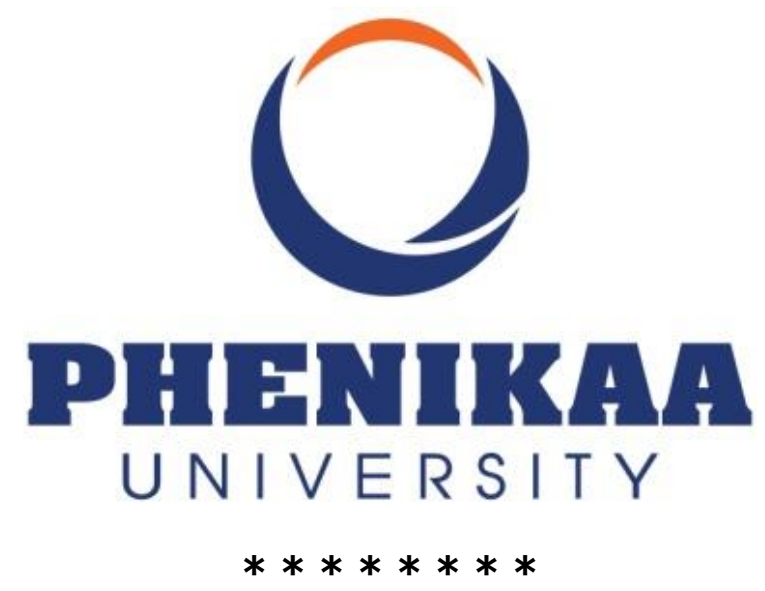

Mới đây, TS. Lê Văn Út, Trưởng nhóm Nhóm nghiên cứu trắc lượng thông tin, Trường Đại học Tôn Đức Thắng, đã trình bày 2 bản danh sách các nhà khoa học nội lực Việt Nam nằm trong top $2 \%$ các nhà khoa học có nhiều trích dẫn nhất thế giới [1]. Hai bản danh sách được tạo dựa trên số lượng trích dẫn xét theo thành tựu trọn đời và số lượng trích dẫn xét theo năm gần nhất. Bản danh sách thành tựu trọn đời gồm có 22 nhà khoa học, trong khi đó bản danh sách top trích dẫn năm 2021 gồm có 65 nhà khoa học. Với tinh thần phát triển nội lực, bản danh sách của TS. Út [1] chỉ tập trung vào các nhà nghiên cứu có quốc tịch Việt Nam và đang là nhân sự cơ hữu thuộc các tổ chức thuộc Việt Nam (gọi tắt: nhà nghiên cứu nội lực). Trước đây, TS. Út và cộng sự [2] cũng đã có một bài nghiên cứu phân tích sâu sắc về xu hướng và tác động của việc hợp tác quốc tế của các nhà khoa học Việt Nam.

Có một câu hỏi khá thú vị, đó là "các nhà khoa học nội lực có trích dẫn cao nhất thế giới xét theo thành tựu trọn đời đang làm việc trong môi trường như thế nào?" Để trả lời cho câu hỏi này, bài viết đã thu thập một số các thông tin về lịch sử và xếp hạng quốc tế của các tổ chức của các nhà khoa học nội lực Việt Nam thuộc top trích dẫn xét theo thành tựu trọn đời.

Trong danh sách 13 tổ chức mà các nhà khoa học nội lực tiêu biểu liên kết, có thể thấy được 2 nhóm tổ chức có đặc điểm môi trường làm việc khác nhau. Nhóm thứ nhất, cũng là nhóm chiếm phần đông, là các trường công lập và có lịch sử lâu đời, điển hình như ĐH 
Quốc gia Hà Nội, ĐH Quốc gia TP.HCM, ĐH Dược Hà Nội, và ĐH Công nghệ Giao thông Vận tải (xem bảng 1). Trong đấy, thành tích của ĐH Quốc gia Hà Nội khá nổi bật sao với các tổ chức khác trên các bảng xếp hạng quốc tế, như xếp hạng 801-1000 thế giới theo QS World University Rankings 2021, 801-1000 thế giới theo THE World University Rankings 2021, và 401-600 thế giới theo THE Impact Rankings 2021. GS. Nguyễn Đình Đức và PGS. Lê Hoàng Sơn là hai nhà khoa học nội lực tiêu biểu thuộc ĐH Quốc gia Hà Nội.

Trong nhóm các tổ chức công lập có lịch sử lâu đời, hai tổ chức xếp sau ĐH Quốc gia Hà Nội trên các bảng xếp hạng quốc tế là ĐH Quốc gia TP.HCM (xễp hạng 370 khu vực Châu Á Thái Bình Dương theo Nature Index Rankings 2021, hạng 801-1000 QS World University Rankings 2021, và 1000+ thế giới theo THE World University Rankings 2021)và ĐH Sư phạm Hà Nội (xếp hạng 2655 thế giới theo URAP 2020-2021). ĐH Quốc gia TP.HCM là môi trường làm việc của hai nhà nghiên cứu nội lực tiêu biểu: PGS. Phạm Văn Hùng và GS. Võ Văn Hoàng. Trong khi đó, PGS. Lê Văn Hiện đang liên kết với trường ĐH Sư Phạm Hà Nội.

Trong nhóm tổ chức thứ nhất, Viện Hàn lâm KH\&CN Việt Nam là nơi làm việc của 3 nhà khoa học nội lực Việt Nam tiêu biểu: Cố GS. Hoàng Tụy, GS. Vũ Ngọc Phát, và GS. Nguyễn Bá Ân. Mặc dù viện không xuất hiện trên các bảng xếp hạng quốc tế, nhưng với bề dày lịch sử (thành lập năm 1975) và việc được đầu tư trọng điểm bởi nhà nước cũng góp phần tạo nên và thu hút các nhà khoa học nội lực. Tính đến nay, Viện Hàn Lâm được xây dựng dựa trên ba nhóm thành viên. Nhóm thứ nhất do Chính Phủ Việt Nam thành lập với 25 viện, 4 trung tâm, 1 nhà xuất bản, và 1 đại học (ĐH Khoa học và Công nghệ Hà Nội). Nhóm thứ hai gồm 2 viện và 2 phân viện được thành lập bởi Viện Hàn lâm Khoa học và Công nghệ Việt Nam. Nhóm thứ ba gồm các ban quản lý và các đơn vị hoạt động hạch toán độc lập.

Bảng 1: Lịch sử thành lập của các tổ chức có các nhà khoa học nội lực Việt Nam tiêu biểu

\begin{tabular}{|c|c|c|c|l|}
\hline Tổ chức & $\begin{array}{c}\text { Số nhà } \\
\text { khoa học }\end{array}$ & $\begin{array}{c}\text { Năm } \\
\text { thành lập }\end{array}$ & Vị trí & \multicolumn{1}{c|}{ Tên cũ } \\
\hline $\begin{array}{c}\text { Viện Hàn lâm KH\&CN } \\
\text { Việt Nam }\end{array}$ & 3 & 1975 & $\begin{array}{c}\text { TP. Hà } \\
\text { Nội }\end{array}$ & $\begin{array}{l}\text { - Viện Khoa học Việt Nam (1975 - } \\
\text { - Viện Khoa học và Công nghệ Việt } \\
\text { Nam (2004 - 2012) } \\
- \text { Viện Hàn lâm Khoa học và Công } \\
\text { nghệ Việt Nam (2012 - hiện tại) }\end{array}$ \\
\hline ĐH Phenikaa & 3 & 2007 & $\begin{array}{c}\text { TP. Hà } \\
\text { Nội }\end{array}$ & $\begin{array}{l}\text { - ĐH Thành Tây (2007 - 2018) } \\
\text { - ĐH Phenikaa (2018 - hiện tại) }\end{array}$ \\
\hline ĐH Duy Tân & 3 & 1994 & $\begin{array}{c}\text { TP. Đà } \\
\text { Nẵng }\end{array}$ & - ĐH Duy Tân (1994 - hiện tại) \\
\hline $\begin{array}{c}\text { ĐH Công nghệ } \\
\text { TP.HCM }\end{array}$ & 2 & 1995 & $\begin{array}{c}\text { TP. Hồ } \\
\text { Chí Minh }\end{array}$ & $\begin{array}{l}\text { - ĐH Công nghệ TP.HCM (1995 - tại) } \\
\text { hiện }\end{array}$ \\
\hline
\end{tabular}




\begin{tabular}{|c|c|c|c|c|}
\hline ĐH Quốc gia Hà Nội & 2 & 1906 & $\begin{array}{l}\text { TP. Hà } \\
\text { Nội }\end{array}$ & $\begin{array}{l}\text { - ĐH Đông Dương (1906 - 1945) } \\
\text { - ĐH Quốc gia Việt Nam (1945 - } \\
\text { 1956) } \\
\text { Khoa học Cơ bản (1951 - 1956) } \\
\text { ĐH Tổng hợp Hà Nội (1956 - 1993) } \\
\text { ĐH Sư phạm Ngoại ngữ Hà Nội } \\
\text { (1956 - 1993) } \\
\text { ĐH Quốc gia Hà Nội (1993 - hiện } \\
\text { tại) }\end{array}$ \\
\hline ĐH Quốc gia TP.HCM & 2 & 1976 & $\begin{array}{l}\text { TP. Hồ } \\
\text { Chí Minh }\end{array}$ & $\begin{array}{l}\text { - ĐH Tổng hợp Thành phố Hồ Chí } \\
\text { Minh (1976 - 1996) } \\
\text { - ĐH Quốc gia TP.HCM (1996 - hiện } \\
\text { tại) }\end{array}$ \\
\hline $\begin{array}{l}\text { Viện năng lượng } \\
\text { nguyên tử Việt Nam }\end{array}$ & 1 & 1962 & $\begin{array}{l}\text { TP. Hà } \\
\text { Nội }\end{array}$ & $\begin{array}{l}\text { - Viện Nguyên tử Đà Lạt (1962 - } \\
\text { 1984) } \\
\text { - Viện Năng lượng nguyên tử Quốc } \\
\text { gia (1984 - 1993) } \\
\text { - Viện Năng lượng nguyên tử Việt } \\
\text { Nam (1993 - hiện tại) }\end{array}$ \\
\hline ĐH Dược Hà Nội & 1 & 1902 & $\begin{array}{l}\text { TP. Hà } \\
\text { Nội }\end{array}$ & $\begin{array}{l}\text { - Trường thuốc Đông Dương (1902 - } \\
\text { 1941) } \\
\text { - ĐH Y - Dược Đông Dương (1941 - } \\
\text { 1946) } \\
\text { - ĐH Y - Dược khoa (1946 - 1961) } \\
\text { - ĐH Dược khoa Hà Nội (1961 - } \\
\text { 1985) } \\
\text { - ĐH Dược Hà Nội (1985 - hiện tại) }\end{array}$ \\
\hline $\begin{array}{c}\text { Viện nghiên cứu AI - } \\
\text { Vingroup }\end{array}$ & 1 & 2019 & $\begin{array}{l}\text { TP. Hà } \\
\text { Nội }\end{array}$ & $\begin{array}{l}\text { - Viện nghiên cứu AI - Vingroup } \\
\text { (2019 - hiện tại) }\end{array}$ \\
\hline $\begin{array}{l}\text { ĐH Công nghệ Giao } \\
\text { thông Vận tải }\end{array}$ & 1 & 1902 & $\begin{array}{l}\text { TP. Hà } \\
\text { Nội }\end{array}$ & $\begin{array}{l}\text { - Thư ký và cán sự chuyên môn } \\
\text { công chính (1902 - 1913) } \\
\text { - Trường Công chính (1913 - 1918) } \\
\text { - Trường Cao đẳng Công chính } \\
\text { (1918 - 1949) } \\
\text { - Trường Cao đẳng Kỹ thuật (1949 - } \\
\text { 1956) } \\
\text { - Trường Trung cấp Thuỷ Lợi - Kiến } \\
\text { Trúc (1956 - 1983) } \\
\text { - Trường Trung học Giao thông Vận } \\
\text { tải I (1983 - 1990) } \\
\text { - Trường Trung học Giao thông Vận } \\
\text { tải khu vực I (1990 - 1996) } \\
\text { - Trường Cao đẳng giao thông vận } \\
\text { tải (1996 - 2011) } \\
\text { - ĐH Công nghệ Giao thông Vận tải } \\
\text { (2011 - hiện tại) }\end{array}$ \\
\hline $\begin{array}{l}\text { ĐH Giao thông Vận tải } \\
\text { TP.HCM }\end{array}$ & 1 & 1974 & $\begin{array}{l}\text { TP. Hồ } \\
\text { Chí Minh }\end{array}$ & $\begin{array}{l}\text { - ĐH Hàng hải (1974 - 1989) } \\
\text { - Trung tâm Đại học Hàng hải phía } \\
\text { Nam (1989 - 1991) } \\
\text { - Phân hiệu Đại học Hàng hải phía } \\
\text { Nam (1991 - 2001) } \\
\text { - ĐH Giao thông Vận tải TP.HCM } \\
\text { (2001- hiện tại) }\end{array}$ \\
\hline
\end{tabular}




\begin{tabular}{|c|c|c|c|c|}
\hline ĐH Sư phạm Hà Nội & 1 & 1951 & $\begin{array}{l}\text { TP. Hà } \\
\text { Nội }\end{array}$ & $\begin{array}{l}\text { - ĐH Sư phạm Khoa học (1951 - } \\
\text { 1956) } \\
\text { - ĐH Sư phạm Hà Nội (1956 - 1967) } \\
\text { - ĐH Sư phạm Hà Nội } 1 \text { (1967 - } \\
\text { 1993) } \\
\text { - ĐH Sư phạm - ĐH Quốc gia Hà Nội } \\
\text { (1993 - 1999) } \\
\text { - ĐH Sư phạm Hà Nội (1999 - hiện } \\
\text { tại) }\end{array}$ \\
\hline ĐH Tôn Đức Thắng & 1 & 1997 & $\begin{array}{l}\text { TP. Hồ } \\
\text { Chí Minh }\end{array}$ & $\begin{array}{l}\text { - ĐH Công nghệ Dân lập Tôn Đức } \\
\text { Thắng (1997 - 2003) } \\
\text { - ĐH Bán công Tôn Đức Thắng } \\
\text { (2003 - 2008) } \\
\text { - Đại học Tôn Đức Thắng (2008 - } \\
\text { hiện tại) }\end{array}$ \\
\hline
\end{tabular}

Nhóm thứ hai gồm các tổ chức khá trẻ và có định hướng áp dụng chuẩn nghiên cứu quốc tế từ sớm. Các tổ chức này gồm có: ĐH Phenikaa, ĐH Duy Tân, ĐH Tôn Đức Thắng, và Viện nghiên cứu AI - Vingroup. Trong bốn tổ chức, ĐH Phenikaa và ĐH Duy Tân có nhiều nhà khoa học nội lực tiêu biểu nhất. Từ năm 2014, ĐH Duy Tân đã tập trung hơn vào nâng cao chất lượng của các hoạt động nghiên cứu thông qua việc thành lập Viện Nghiên cứu và Phát triển Công nghệ Cao trên cơ sở nâng cấp Trung tâm Nghiên cứu và Phát triển (thành lập năm 2011). Điều đấy đã giúp trường xây dựng được môi trường và văn hóa học thuật có khả năng đào tạo và thu hút các nhà khoa học nội lực, như TS. Trân Nguyễn Hải, TS. Hoàng Nhật Đức, và TS. Nguyễn Đăng Nam. Cũng từ các nỗ lực này, trường đã gặt hái được một số thành tựu trên quốc tế, như: xếp hạng 1482 thế giới theo CWUR 2021-2022 và hạng 770 thế giới theo URAP 2020-2021.

Bảng 2: Xếp hạng quốc tế của các tổ chức có các nhà khoa học nội lực Việt Nam tiêu biểu

\begin{tabular}{|c|c|}
\hline Tổ chức & Xếp hạng quốc tế \\
\hline Viên Hàn lâm KH\&CN Viêt Nam & $-N A$ \\
\hline ĐH Phenikaa & $\begin{array}{l}\text { - Xếp hạng } 142 \text { khu vực Châu Á theo RePEc/IDEAS rankings } 2021 \\
\text { - Xếp hạng } 328 \text { khu vực Châu Á Thái Bình Dương theo Nature Index } \\
\text { Rankings } 2021 \\
\text { - Xếp hạng 801-1000 thế giới theo THE Impact Rankings } 2021\end{array}$ \\
\hline ĐH Duy Tân & $\begin{array}{l}\text { - Xếp hạng } 1482 \text { thế giới theo CWUR 2021-2022 } \\
\text { - Xếp hạng } 770 \text { thế giới theo URAP 2020-2021 }\end{array}$ \\
\hline ĐH Công nghệ TP.HCM & $-N A$ \\
\hline ĐH Quốc gia Hà Nội & $\begin{array}{l}\text { - Xếp hạng 801-1000 thế giới theo QS World University Ranking } \\
2021 \\
\text { - Xễp hạng } 1266 \text { thế giới theo CWUR 2021-2022 } \\
\text { - Xếp hạng } 1066 \text { thế giới theo URAP 2020-2021 } \\
\text { - Xếp hạng 801-1000 thế giới theo THE World University Ranking } \\
2021 \\
\text { - Xếp hạng 401-600 thế giới theo THE Impact Ranking } 2021\end{array}$ \\
\hline ĐH Quốc gia TP.HCM & $\begin{array}{l}\text { - Xếp hạng } 370 \text { khu vực Châu Á Thái Bình Dương theo Nature Index } \\
\text { Ranking } 2021\end{array}$ \\
\hline
\end{tabular}




\begin{tabular}{|c|l|}
\hline & $\begin{array}{l}\text { - Xếp hạng 801-1000 QS World University Ranking } 2021 \\
\text { - Xếp hạng 1619 thế giới theo CWUR 2021-2022 } \\
\text { - Xếp hạng } 1136 \text { thế giới theo URAP 2020-2021 } \\
\text { - Xếp hạng 1000+ thế giới theo THE World University Ranking } 2021\end{array}$ \\
\hline $\begin{array}{c}\text { Viện năng lượng nguyên tứ } \\
\text { Việt Nam }\end{array}$ & - NA \\
\hline ĐH Dược Hà Nội & - NA \\
\hline Viện nghiên cứu AI - Vingroup & - NA \\
\hline ĐH Công nghệ Giao thông Vận & - NA \\
\hline tải & - NA \\
\hline ĐH Giao thông Vận tải TP.HCM & - Xếp hạng 2655 thế giới theo URAP 2020-2021 \\
\hline ĐH Sứ phạm Hà Nội & - Xếp hạng 477 khu vực Châu Á Thái Bình Dương theo Nature Index \\
& $\begin{array}{c}\text { Ranking 2021 } \\
\text { - Xếp hạng 1000+ QS World University Ranking 2021 } \\
\text { - Xếp hạng 1426 thế giới theo CWUR 2021-2022 } \\
\text { - Xếp hạng 639 thế giới theo URAP 2020-2021 } \\
\text { - Xếp hạng 401-600 thế giới theo THE Impact Ranking } 2021\end{array}$ \\
\hline ĐH Tôn Đức Thắng
\end{tabular}

Mặc dù ĐH Phenikaa bắt đầu tập trung đầu tư vào hoạt động nghiên cứu khoa học trễ hơn hơn so với ĐH Duy Tân nhưng cũng đã tạo ra được môi trường và văn hóa nghiên cứu học thuật có khả năng đào tạo và thu hút các nhà khoa học nội lực, như GS. Nguyễn Văn Hiếu, TS. Đào Văn Dương, và TS. Vương Quân Hoàng. Việc chuyển đổi này bắt đâu từ năm 2017 (lúc đấy trường vẫn mang tên là ĐH Thành Tây), khi đơn vị nghiên cứu đầu tiên của trường, Trung tâm Nghiên cứu Khoa học Xã hội liên ngành (ISR), được thành lập [3-5]. Trong các năm tiếp theo, trường Phenikaa tiếp tục đẩy mạnh xây dựng môi trường và văn hóa nghiên cứu thông qua việc thành lập 3 viện nghiên cứu khoa học: Viện Nghiên cứu Công nghệ PHENIKAA (PRATI), Viện Nghiên cứu Tiên tiến PHENIKAA (TIAS), và Viện Nghiên cứu Nano [6].

ĐH Tôn Đức Thắng cũng là một trong những tổ chức có môi trường và văn hóa học thuật nổi trội có khả năng đào tạo và thu hút các nhà nghiên cứu nội lực Việt Nam, điển hình như TS. Thái Hoàng Chiến. Được biết, TS. Thái Hoàng Chiến về công tác tại ĐH Tôn Đức Thắng từ 2010 với học vị thạc sĩ và chưa từng du học tại nước ngoài [7], nên có thể nói ĐH Tôn Đức Thắng là ngôi trường rất chú trọng vào việc thúc đẩy và phát triển nội lực khoa học. Điều này cũng có thể thấy được thông qua mục tiêu trong hai thập niên tới của trường là trở thành một đại học nghiên cứu thuộc TOP 500 thế giới.

Lưu ý: các thông tin về lịch sử và tên cũ của các tổ chức trong bài được trích xuất từ Wikipedia và website của tổ chức. Các thông tin về xếp hạng quốc tế thì được trích xuất từ các website sau:

- RePEc/IDEAS rankings 2021 khu vực Châu Á: https://ideas.repec.org/top/top.asia.html 
- Nature Index Rankings 2021 khu vực Châu Á Thái Bình Dương:

https://www.natureindex.com/annualtables/2021/institution/academic/all/regions-Asia\%20Pacific

- THE Impact Rankings 2021: https://www.timeshighereducation.com/impactrankings\#!/page/0/length/25/loca tions/VNM/sort by/rank/sort order/asc/cols/undefined

- THE World University Ranking 2021: https://www.timeshighereducation.com/world-university-rankings/2021/worldranking\#!/page/0/length/25/locations/VNM/sort by/rank/sort order/asc/cols/stat $\underline{s}$

- CWUR 2021-2022: https://cwur.org/2021-22.php

- URAP 2020-2021: https://urapcenter.org/Rankings/20202021/World Ranking 2020-2021

- QS World University Ranking 2021: https://www.topuniversities.com/universityrankings/world-university-rankings/2021

\section{References}

1. Lê Văn Út. (2021). Sự thật về nội lực Việt Nam trong trích dẫn khoa học hàng đầu thế giới 2021. Dân Trí. Trích xuất từ: https://dantri.com.vn/giao-duc-huongnghiep/su-that-ve-noi-luc-viet-nam-trong-trich-dan-khoa-hoc-hang-dau-the-gioi2021-20211030083557165.htm

2. Nguyen TV, Ho-Le TP, Le UV. (2017). International collaboration in scientific research in Vietnam: an analysis of patterns and impact. Scientometrics, 110, 1035-1051.

3. Vuong QH. (2018). The (ir)rational consideration of the cost of science in transition economies. Nature Human Behaviour, 2, 5.

4. Vuong QH. (2019). Breaking barriers in publishing demands a proactive attitude. Nature Human Behaviour, 3, 1034.

5. Vuong QH. (2020). Reform retractions to make them more transparent. Nature, $582,149$.

6. Đình Hà. (2018). Tập đoàn PHENIKAA ra mắt 2 viện nghiên cứu PRATI và TIAS. Cổng Thông Tin Điện Tử Bộ Xây Dựng. Trích xuất từ: https://moc.gov.vn/tl/tintuc/14166/tap-doan-phenikaa-ra-mat-2-vien-nghien-cuu-prati-va-tias.aspx

7. Hồng Hạnh. (2019). TS. Thái Hoàng Chiến: Nhà khoa học "made in Vietnam" có tầm ảnh hưởng quốc tế. Dân Trí. Trích xuất từ: https://dantri.com.vn/giao-duchuong-nghiep/ts-thai-hoang-chien-nha-khoa-hoc-made-in-vietnam-co-tam-anhhuong-quoc-te-20191012052545573.htm 